Pacific Journal of Mathematics

ERRATUM: "UNIQUENESS AND EXISTENCE PROPERTIES OF 
should be replaced by $\mathscr{Z}$, and $\widetilde{Z}$ should be replaced by $\mathscr{Z}$. The symbols $\tilde{\mathfrak{A}}_{m}$ and $\tilde{\mathfrak{A}}_{m}^{0}$ should be replaced throughout by $\mathfrak{\mathfrak { A }}_{m}$ and $\mathfrak{N}_{m}^{0}$, respectively; however, $\widetilde{\mathfrak{A}}_{n}$ and $\widetilde{\mathfrak{U}}_{n}^{0}$ remain unchanged. The first equation of line 14 page 235 should be '角 $=\widetilde{\mathfrak{A}}_{n}^{\prime}$."

Correction to

\title{
DUALITY AND TYPES OF COMPLETENESS IN LOCALLY CONVEX SPACES
}

\author{
William B. JONES
}

Volume 18 (1966), 525-544

Proposition 2.14 is an obvious consequence of Lemma 2.8 .

p. 538, line 5: The second equality is false in general for all $\alpha$ (see [4]).

Some misprints:
p. 526
$\S 2$ should start " $(\alpha, \beta)-\ldots$ "
p. 528
line 3 of $\S 2$, " $\alpha$ " instead of " $\alpha$ "
p. 532 last line, remove final " $\}$ "
p. 535 line 14 , second " $\varepsilon$ " should be " $\in$ " line 2 , should read

$$
\cdots \leqq \frac{\varepsilon}{r}(r-\cdots
$$
p. 537
line 8 , second "=" should be "-_"
p. 541
line 9 , " $\lambda_{0}$ " instead of " $1_{0}$ "

Correction to

\section{UNIQUENESS AND EXISTENCE PROPERTIES OF BOUNDED OBSERVABLES}

\author{
S. P. GUDDER \\ Volume 19 (1966), 81-93
}

The author recently discovered that the proof of the corollary to Theorem 4.5 is incorrect, thus invalidating Theorem 4.6. We show now that Theorem 4.6 is still true for a class of observables with infinite spectra and prove a generalization of Theorem 4.5.

An observable $x$ is semi-bounded above (below) if there is a number 
$-\infty<c<\infty$ such that $\sigma(x) \subset\{\lambda: \lambda \leqq c\} \quad(\sigma(x) \subset\{\lambda: \lambda \geqq c\})$. The following not only generalizes Theorem 4.5 but gives a much simpler proof.

THEOREM 1.1. Let $x$ and $y$ be observables on a quite full logic which are semi-bounded above and suppose that $m(x)$ exists if and only if $m(y)$ exists and in that case $m(x)=m(y)$. Then $\lambda_{0}=$ $\max \{\lambda: \lambda \in \sigma(x)\}=\max \{\lambda: \lambda \in \sigma(y)\}$ and $x\left(\lambda_{0}\right)=y\left(\lambda_{0}\right)$.

Proof. The first part of the conclusion follows just as in Theorem 4.5. Now suppose $m\left[x\left(\lambda_{0}\right)\right]=1$, and $m\left[y\left(\lambda_{0}\right)\right] \neq 1$. Then there is a number $\mu<\lambda_{0}$ such that $m[y(-\infty, \mu)]>0$. Now since $m(x)$ exists, so does $m(y)$ and we have

$$
\begin{aligned}
\lambda_{0}=m(x)=m(y) & =\int_{\left(-\infty, \lambda_{0}\right]} \lambda m[y(d \lambda)]=\left(\int_{(-\infty, \mu)}+\int_{\left[\mu, \lambda_{0}\right]}\right) \lambda m[y(d \lambda)] \\
& \leqq \mu m[y(-\infty, \mu)]+\lambda_{0} m\left[y\left[\mu, \lambda_{0}\right)\right]<\lambda_{0} .
\end{aligned}
$$

which is a contradiction. Thus $m\left[y\left(\lambda_{0}\right)\right]=1$ whenever $m\left[x\left(\lambda_{0}\right)\right]=1$ and hence $x\left(\lambda_{0}\right) \leqq y\left(\lambda_{0}\right)$. By symmetry $x\left(\lambda_{0}\right)=y\left(\lambda_{0}\right)$.

Of course the same result holds for observables which are semibounded from below.

THEOREM 1.2. Let $x$ and $y$ be bounded observables on a quite full logic and suppose the spectrum of $x$ has at most one limit point. If $m(x)=m(y)$ for all $m \in M$ then $x=y$.

Proof. The most general such $x$ has a point $\lambda_{0} \in \sigma(x)$ which is a limit point from both above and below of elements of $\sigma(x)$. The other cases will follow in a similar manner. We can assume without loss of generality that $\lambda_{0}=0$. Let the points of $\sigma(x)$ be ordered as follows: $\mu_{1}<\mu_{2}<\cdots<\lambda_{0}<\cdots<\lambda_{2}<\lambda_{1}$. Now by Theorem 1.1 $\max \{\lambda: \lambda \in \sigma(y)\}=\lambda_{1}$ and $y\left(\lambda_{1}\right)=x\left(\lambda_{1}\right)$. Now let $x_{1}=x-\lambda_{1} \chi_{\lambda_{1}}(x)$ and let $y_{1}=y-\lambda_{1} \chi_{\lambda_{1}}(y)$. Letting $f$ be the identity function $f(\lambda)=\lambda$ we have for $E \in B(R)$

$$
\begin{aligned}
x_{1}(E) & =\left(f-\lambda_{1} \chi_{\lambda_{1}}\right)(x)(E)=x\left[\left(f-\lambda_{1} \chi_{\lambda_{1}}\right)^{-1}(E)\right] \\
& = \begin{cases}x(E) \wedge x\left(\lambda_{1}\right)^{\prime} & \text { if } 0 \in E \\
x(E) \vee x\left(\lambda_{1}\right) & \text { if } 0 \in E\end{cases}
\end{aligned}
$$

It is now easy to see that

$$
\left.\sigma\left(x_{1}\right)=\sigma(x) \cap\left\{\lambda_{1}\right\}^{\prime} ; x_{1}\left(\lambda_{i}\right)=x \lambda_{i}\right), i=2,3, \cdots ;
$$

and

$$
x_{1}\left(\mu_{i}\right)=x\left(\mu_{i}\right), i=1,2, \cdots .
$$


Now

$$
m\left(x_{1}\right)=m(x)-\lambda_{1} m\left[x\left(\lambda_{1}\right)\right]=m(y)-\lambda_{1} m\left[y\left(\lambda_{1}\right)\right]=m\left(y_{1}\right) .
$$

Applying Theorem 1.1, $\lambda_{2}=\max \left\{\lambda: \lambda \in \sigma\left(y_{1}\right)\right\}$ and $y_{1}\left(\lambda_{2}\right)=x_{1}\left(\lambda_{2}\right)=x\left(\lambda_{2}\right)$. It now follows by applying (1) to $y_{1}$ and $y$ that $\lambda_{2}$ is the second largest number in $\sigma(y)$ and $y\left(\lambda_{2}\right)=y_{1}\left(\lambda_{2}\right)=x\left(\lambda_{2}\right)$. Continuing this process with the $\lambda_{i}$ 's and also the $\mu_{i}$ 's we have $\left\{\lambda_{i}, \mu_{i}: i=1,2, \cdots\right\} \subset \sigma(y)$ and $y\left(\lambda_{i}\right)=x\left(\lambda_{i}\right), y\left(\mu_{i}\right)=x\left(\mu_{i}\right), i=1,2, \cdots$. Since $\lambda_{0}$ is a limit point of the $\lambda_{i}$ 's it follows that $\lambda_{0} \in \sigma(y),\left\{\lambda_{i}, \mu_{i}: i=1,2, \cdots\right\}=\sigma(y)$ and

$$
\begin{aligned}
y\left(\lambda_{0}\right) & =y\left(\left\{\lambda_{i}, \mu_{i}: i=1,2, \cdots\right\}^{\prime}\right)=\left[\Sigma y\left(\lambda_{i}\right)+\Sigma y\left(\mu_{i}\right)\right]^{\prime} \\
& =\left[\Sigma x\left(\lambda_{i}\right)+\Sigma x\left(\mu_{i}\right)\right]^{\prime}=x\left(\lambda_{0}\right) .
\end{aligned}
$$

Hence $y=x$.

A similar technique may be used to prove:

COROLlaRY 1.3. Let $x$ and $y$ be observables on a quite full logic which are semi-bounded from above (below) and suppose the spectrum of $x$ has no finite limit point (this includes the possibility of a limit point at $-\infty(+\infty))$. Suppose $m(y)$ exists if and only if $m(x)$ exists and in that case $m(y)=m(x)$. Then $x=y$.

We close with a slightly strengthened form of Lemma 6.2 [1].

LEMMA 1.4. If $L$ is quite full and has Property $E$, then $L$ is $a$ lattice and $m(a)=m(b)=1$ implies $m(a \wedge b)=1$.

Proof. That $L$ is a lattice follows from Lemma 6.2 [1]. If $m(a)=m(b)=1$, then $m\left(x_{a}+x_{b}\right)=m(a)+m(b)=2$ and hence $1=m\left[\left(x_{a}+x_{b}\right)\{2\}\right]=m(a \wedge b)$.

This last lemma is of interest since it rules out the counterexample of Section 5 [1] and is thus a possible sufficient condition for Property E. 


\section{PACIFIC JOURNAL OF MATHEMATICS}

\section{EDITORS}

H. SAMELSON

Stanford University

Stanford, California

J. P. JANS

University of Washington

Seattle, Washington 98105

\section{J. DuGUNDJI}

University of Southern California

Los Angeles, California 90007

RICHARD ARENS

University of California

Los Angeles, California 90024

\section{ASSOCIATE EDITORS}

E. F. BECKENBACH
B. H. NEUMANN

F. WOLF

K. YoSIDA

\section{SUPPORTING INSTITUTIONS}

\author{
UNIVERSITY OF BRITISH COLUMBIA \\ CALIFORNIA INSTITUTE OF TECHNOLOGY \\ UNIVERSITY OF CALIFORNIA \\ MONTANA STATE UNIVERSITY \\ UNIVERSITY OF NEVADA \\ NEW MEXICO STATE UNIVERSITY \\ OREGON STATE UNIVERSITY \\ UNIVERSITY OF OREGON \\ OSAKA UNIVERSITY \\ UNIVERSITY OF SOUTHERN CALIFORNIA
}

\author{
STANFORD UNIVERSITY \\ UNIVERSITY OF TOKYO \\ UNIVERSITY OF UTAH \\ WASHINGTON STATE UNIVERSITY \\ UNIVERSITY OF WASHINGTON \\ AMERICAN MATHEMATICAL SOCIETY \\ CHEVRON RESEARCH CORPORATION \\ TRW SYSTEMS \\ NAVAL ORDNANCE TEST STATION
}

Mathematical papers intended for publication in the Pacific Journal of Mathematics should be typewritten (double spaced). The first paragraph or two must be capable of being used separately as a synopsis of the entire paper. It should not contain references to the bibliography. Manuscripts may be sent to any one of the four editors. All other communications to the editors should be addressed to the managing editor, Richard Arens at the University of California, Los Angeles, California 90024 .

50 reprints per author of each article are furnished free of charge; additional copies may be obtained at cost in multiples of 50 .

The Pacific Journal of Mathematics is published monthly. Effective with Volume 16 the price per volume (3 numbers) is $\$ 8.00$; single issues, $\$ 3.00$. Special price for current issues to individual faculty members of supporting institutions and to individual members of the American Mathematical Society: $\$ 4.00$ per volume; single issues $\$ 1.50$. Back numbers are available.

Subscriptions, orders for back numbers, and changes of address should be sent to Pacific Journal of Mathematics, 103 Highland Boulevard, Berkeley 8, California.

Printed at Kokusai Bunken Insatsusha (International Academic Printing Co., Ltd.), No. 6, 2-chome, Fujimi-cho, Chiyoda-ku, Tokyo, Japan.

\section{PUBLISHED BY PACIFIC JOURNAL OF MATHEMATICS, A NON-PROFIT CORPORATION}

The Supporting Institutions listed above contribute to the cost of publication of this Journal, but they are not owners or publishers and have no responsibility for its content or policies. 


\section{Pacific Journal of Mathematics

Vol. 19, No. $3 \quad$ July, 1966

S. J. Bernau, The spectral theorem for unbounded normal operators .......

Lu-san Chen, Asymptotic behavior of solutions of parabolic equations of

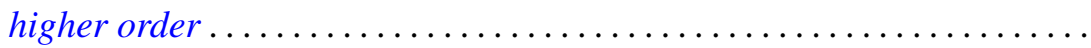

Lawrence William Conlon, An application of the Bott suspension map to the

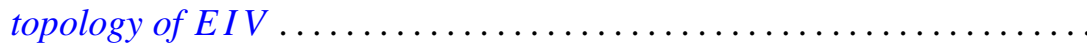

Neal Eugene Foland and John M. Marr, Sets with zero-dimensional kernels .........................................

Stanley Phillip Franklin and R. H. Sorgenfrey, Closed and image-closed

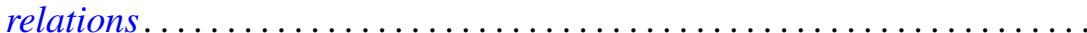

William Jesse Gray, A note on topological transformation groups with a

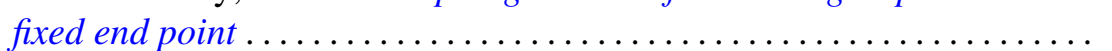

Myron Goldstein, $K$ - and L-kernels on an arbitrary Riemann surface ...... 449

George Joseph Kertz and Francis Regan, The exponential analogue of a generalized Weierstrass series .............................

Walter Leighton, On Liapunov functions with a single critical point ........ 467

Bernard Werner Levinger and Richard Steven Varga, On a problem of $O$.

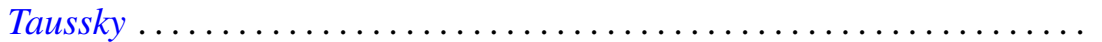

Lowell Duane Loveland, Tame subsets of spheres in $E^{3} \ldots \ldots \ldots \ldots \ldots . .489$

Erik Andrew Schreiner, Modular pairs in orthomodular lattices ......... 519

K. N. Srivastava, On dual series relations involving Laguerre polynomials ...............................

Arthur Steger, Diagonability of idempotent matrices.....

Walter Strauss, On continuity of functions with values in various Banach spaces...

Robert Vermes, On the zeros of a linear combination of polynomials ...

Elliot Carl Weinberg, On the scarcity of lattice-ordered matrix rings ....

Harold Widom, Toeplitz operators on $H_{p} \ldots \ldots \ldots \ldots \ldots$

Neal Zierler, On the lattice of closed subspaces of Hilbert space...

Irving Leonard Glicksberg, Correction to: "Maximal algebras and a theorem of Rado"

John Spurgeon Bradley, Correction to: "Adjoint quasi-differential operators of Euler type"

William Branham Jones, Erratum: "Duality and types of completeness in locally covex spaces".

Stanley P. Gudder, Erratum: "Uniqueness and existence properties of bounded observables" 